\title{
Sensitivity of Summer Precipitation over Korea to Convective Parameterizations in the RegCM4: An Updated Assessment
}

\author{
Thanh Nguyen-Xuan $\mathbb{D}^{1},{ }^{1}$ Liying Qiu, ${ }^{2}$ Eun-Soon Im $\mathbb{D},{ }^{1,2}$ Jina Hur, ${ }^{3}$ and Kyo-Moon Shim ${ }^{3}$ \\ ${ }^{1}$ Division of Environment and Sustainability, The Hong Kong University of Science and Technology, Hong Kong \\ ${ }^{2}$ Department of Civil and Environmental Engineering, The Hong Kong University of Science and Technology, Hong Kong \\ ${ }^{3}$ National Institute of Agricultural Sciences, Rural Development Administration, Wanju-gun, Republic of Korea
}

Correspondence should be addressed to Eun-Soon Im; ceim@ust.hk

Received 9 October 2019; Revised 7 January 2020; Accepted 14 January 2020; Published 27 April 2020

Academic Editor: Mario M. Miglietta

Copyright ( 92020 Thanh Nguyen-Xuan et al. This is an open access article distributed under the Creative Commons Attribution License, which permits unrestricted use, distribution, and reproduction in any medium, provided the original work is properly cited.

\begin{abstract}
This study investigates the performance of the latest version of RegCM4 in simulating summer precipitation over South Korea, comparing nine sensitivity experiments with different combinations of convective parameterization schemes (CPSs) between land and ocean. In addition to the gross pattern of seasonal and monthly mean precipitation, the northward propagation of the intense precipitation band and statistics from extreme daily precipitation are thoroughly evaluated against gridded and in situ station observations. The comparative analysis of 10-year simulations demonstrates that no CPS shows superiority in both quantitative and qualitative aspects. Furthermore, a nontrivial discrepancy among the different observation datasets makes a robust assessment of model performance difficult. Regardless of the CPS over the ocean, the simulations with the Kain-Fritsch scheme over land show a severe dry bias, whereas the simulations with the Tiedtke scheme over land suffer from a limited accuracy in reproducing spatial distributions due to the excessive orographic precipitation. In general, the simulations with the Emanuel scheme over land are better at capturing the major characteristics of summer precipitation over South Korea, despite not all statistical metrics showing the best performance. When applying the Emanuel scheme to both land and the ocean, precipitation tends to be slightly overestimated. This deficiency can be alleviated by using either the Tiedtke or Kain-Fritsch schemes over the ocean instead. As few studies have applied and evaluated the Tiedtke and Kain-Fritsch schemes to the Korean region within the RegCM framework, and this study introduces the potential of these new CPSs compared with the more frequently selected Emanuel scheme, which is particularly beneficial to RegCM users.
\end{abstract}

\section{Introduction}

During recent decades, substantial efforts have been made to improve the performance in simulating the detailed characteristics of regional to local climate over the Korean Peninsula. Dynamical downscaling using regional climate models (RCMs), in particular, has offered the potential to resolve the physical processes modulated by complicated geographical features [1-4], eventually resulting in improved climate statistics compared with those from largescale forcings (e.g., global climate models or reanalysis data). Despite advances in modeling, summer precipitation remains a great challenge due to distinct temporal and regional variations and its stochastic nature [5-8]. Not only approximately $70 \%$ of the annual precipitation is concentrated in the summer season [9] but also its interannual and intraseasonal variations are significant. In addition, summer precipitation over Korea is shaped by many different mechanisms, including the East Asian summer monsoon (EASM) frontal systems, mesoscale convective systems, and typhoon activities $[8,10-12]$. The complex interactions between them make it difficult to reproduce both quantitative and qualitative aspects of summer precipitation. Although RCMs with higher resolution are able to employ the refined surface forcing, the mechanisms mentioned above are not greatly dominated by stationary forcings (e.g., topography); instead, they are dominated by stochastic factors such as convective instability. As a result, most RCMs face many difficulties capturing the temporal and spatial behaviors of summer 
precipitation at regional to local scales with a high level of accuracy. Specifically, the main difficulties include (1) characteristics of daily precipitation (i.e., overestimation of frequency and underestimation of intensity) [3, 4, 7]; (2) intensity and position of some localized extreme precipitation [7]; (3) phase and amplitude of the diurnal variation of precipitation [8]; and (4) occurrence and extent of typhoons [13].

Precipitation simulation is sensitive to many different experimental configurations (e.g., the lateral boundary conditions, horizontal resolution, and parametrization schemes) [14]. Because of the complex formation process of precipitation, there is no single method that can bring a dramatic improvement in simulating precipitation with respect to all aspects. However, selecting a suitable convective parameterization scheme (CPS) is most directly related to the precipitation formation in the model, especially in summer when precipitation is predominantly convective in nature [15-18]. Therefore, finding the optimal CPS over the target region is essential for determining the model configuration if there is flexibility in the choice of multiple schemes under the same modeling framework.

The different versions of the Abdus Salam International Center for Theoretical Physics (ICTP) Regional Climate Model (RegCM) is one of the most widely used RCMs applied to the Asian region, including the Korean peninsula. Two noticeable improvements related to CPS in RegCM version 4 (RegCM4) are running different CPSs over land and ocean, referred to as "mixed convection schemes (MCS)" [19], and including new CPSs, the Tiedtke scheme (added from RegCM4.3) and Kain-Fritsch scheme (added from RegCM4.5). Further options and increased complexity require additional tests for appropriate practical application of the upgraded version. MCS have been widely tested in a significant body of research over different regions [20-25], but the advantages and necessity of MCS are highly dependent on the domain and other configurations of the simulation. The evaluation of the Tiedtke and Kain-Fritsch schemes, newly incorporated in RegCM4, is relatively limited because these versions have only recently been released to the public. While Ali et al. [20] demonstrated that the Tiedtke scheme shows a better performance in simulating summer precipitation over China, FuentesFranco et al. [26] suggested the benefits of using the Kain-Fritsch scheme in simulations of tropical cyclones over Central America. From these exemplary studies, the implementation of MCS and the new CPSs are likely to benefit the regional climate simulation over the selected regions. However, good performance of a CPS in one region does not guarantee its success in other regions, because their performance is greatly influenced by region, seasonality, and their combinations with other schemes. For the regional climate simulation focusing on South Korea, the Emanuel scheme is the most commonly selected CPS within the RegCM configuration [4, 6, 7, 27]. Any sensitivity tests for MCS and new CPSs have not been evaluated and documented yet, providing significant room for a systematic investigation and updated assessment.
In this study, we investigate the relative performance of MCS based on comparative analysis of the nine sensitivity experiments with different combinations of three CPSs (Emanuel, Tiedtke, and Kain-Fritsch) using the latest version RegCM4.7. We focus on the CPSs' sensitivity to summer precipitation over South Korea. The statistics, on monthly and daily time scales, are evaluated against both gridded and station observations. It helps understand the structural error from CPSs and relative strength and weakness of individual CPS. Therefore, the updated assessment of the new CPSs in the latest version RegCM4 can provide an opportunity to augment previous findings and add to baseline information for the usage of RegCM4.

\section{Methodology and Data}

2.1. Model Description and Experimental Design. The model used in this study is the latest version of RegCM (RegCM4.7, hereinafter referred to as RegCM4) developed by the ICTP. The new features of RegCM4 and detailed descriptions of the model's physical processes can be found in Giorgi et al. [28]. Since this study aims to evaluate the model's sensitivity to three CPSs (Emanuel, Tiedtke, Kain-Fritsch) and their combinations over land and ocean, we only address the background behind CPS selection in this paper. Currently, five CPSs are available in RegCM4: the Kuo scheme [29], Grell scheme [30], Emanuel scheme [31], Tiedtke scheme [32], and Kain-Fritsch scheme [33]. In our study, we exclude the Kuo and Grell schemes based on previous studies. It has been demonstrated that the Kuo scheme generally provides poor performance of precipitation simulation, particularly in high resolution $(<30 \mathrm{~km})[25,28]$, and the Grell scheme tends to underestimate summer precipitation over the Korean region, showing poorer performance than the Emanuel scheme $[27,34]$. Therefore, we have designed nine experiments that include all combinations of the three CPSs (Emanuel, Tiedtke, Kain-Fritsch) over land and ocean as described in Table 1. When naming the individual experiments, the bold letters ( $\mathbf{E}, \mathbf{T}$, and $\mathbf{K}$ ) denote the three different CPSs by the first letter of the CPS names, and land and ocean are denoted by the small italic letters $l$ and $o$, respectively. This experimental design makes it possible to quantify the sensitivity of these MCSs and estimate the relative performance of Tiedtke and Kain-Fritsch schemes, which have not yet been applied to the Korean region. The relative performances of these schemes are compared with that of the Emanuel scheme, which is the CPS most frequently selected for the Korean climate simulation, using RegCM. Other physics parameterizations employed are the National Center for Atmospheric Research (NCAR) Community Climate Model version 3 (CCM3) radiation scheme [35], the Holtslag planetary boundary layer scheme [36], the Subgrid Explicit Moisture Scheme (SUBEX) [37] for gridscale cloud process, and the Zeng ocean flux scheme [38]. All of the simulations are coupled with the land surface model Community Land Model version 4.5 (CLM4.5) [39].

Figure 1 presents the domain and topography used in our experiment. The domain covers northeastern Asia centered on the Korean Peninsula and adjacent seas with 
TABLE 1: Experimental design.

\begin{tabular}{lcccc}
\hline & & & CPS over land $(l)$ & \\
& & MIT-Emanuel $(\mathbf{E})$ & Kain-Fritsch $(\mathbf{K})$ & Tiedtke $(\mathbf{T})$ \\
\hline \multirow{3}{*}{ CPS over ocean $(o)$} & MIT-Emanuel $(\mathbf{E})$ & $l \mathbf{E}-o \mathbf{E}$ & $l \mathbf{K}-o \mathbf{E}$ & $l \mathbf{T}-o \mathbf{E}$ \\
& Kain-Fritsch $(\mathbf{K})$ & $l \mathbf{E}-o \mathbf{K}$ & $l \mathbf{K}-o \mathbf{K}$ & $l \mathbf{T}-o \mathbf{K}$ \\
& Tiedtke $(\mathbf{T})$ & $l \mathbf{E}-o \mathbf{T}$ & $l \mathbf{K}-o \mathbf{T}$ & $l \mathbf{T}-o \mathbf{T}$ \\
\hline
\end{tabular}

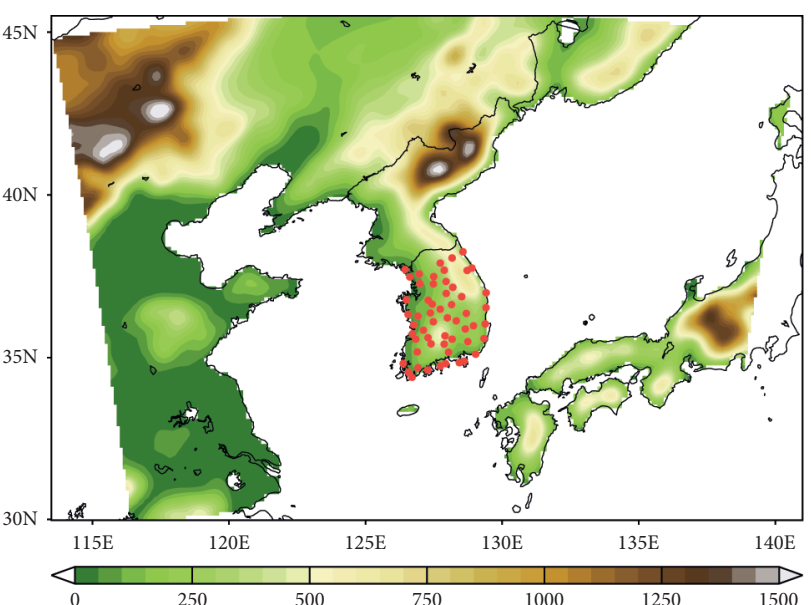

Figure 1: Domain and topography (m) for the simulations, and location of 56 observation stations over South Korea (red dots).

$20 \mathrm{~km}$ horizontal resolution. The initial and boundary conditions are obtained from the ERA-Interim reanalysis with a resolution of $0.75^{\circ} \times 0.75^{\circ}$ at 6-hour intervals [40]. The simulations span from December 1997 to December 2007. The first month is considered as the spin-up period, and the 10 -year period from 1998-2007 is used for analysis.

2.2. Observation Data. Four observation datasets are used in this study to validate the simulated precipitation; (1) the Climate Research Unit (CRU) [41], (2) the Asian Precipitation Highly-Resolved Observation Data Integration Towards Evaluation (APHRODITE) [42], (3) the Tropical Rainfall Measuring Mission (TRMM) [41-44], and (4) the in-situ observation data from 56 stations (see Figure 1) maintained by the Korea Meteorological Administration (KMA) [45]. Detailed information about the four datasets is presented in Table 2.

Since CRU, APHRODITE, and TRMM have a different grid system, they are interpolated to achieve the same resolution as the model using the inverse-distance-weighting method, which facilitates to calculate statistics such as the spatial correlation between the observation datasets and the model output. In addition to the multiple gridded observation datasets, we also use in-situ station observations for in-depth daily analysis. As well documented by Juneng et al. [46], a large discrepancy is found among CRU, APHRODITE, and TRMM, indicating that there is uncertainty embedded in the observation data. Therefore, comparing the simulation with both multiple gridded and in-situ observations will enhance the reliability of the evaluation.

\section{Results}

3.1. Evaluation of the Monthly and Seasonal Mean Precipitation. In this section, the analysis focuses on the comparison between simulated and observed precipitation characteristics, at monthly or seasonal mean timescales. Figure 2 presents the annual cycle of monthly mean precipitation averaged over South Korea. For the 10-year climatology, the precipitation pattern shows a strong seasonal variation. This is because the Korean climate is characterized by cold dry winters and warm wet summers due to the influence of the East Asian monsoon system. In accordance with the amount of precipitation, the sensitivity of each CPS varies from season to season. While the difference in the performance among the CPSs seems to be negligible in the winter, performance deviation among different CPSs is significant during the summer. Similarly, the deviation of the CPS simulation is more pronounced in wet years than dry years. All simulations are reasonably good at simulating the dominant annual cycle of precipitation with a maximum peak in July or August. However, the CPS is able to derive a different performance mainly in the quantitative aspect, differentiating their performance in terms of the amount of summer precipitation. A severe underestimation of summer precipitation occurs in the simulation with the Kain-Fritsch scheme over land (" $\mid \mathbf{K}$ "), regardless of the CPS over ocean. On the other hand, the simulations with the Emanuel and Tiedtke scheme over land (" $l E$ " and " $l T$ ") show a mixed performance with both underestimation and overestimation patterns. Furthermore, the discrepancy among the different observation datasets is not trivial, which makes it difficult to provide an unambiguous assessment of model performance. The best performing simulation varies according to which the observation dataset is used for the comparison.

Figure 3 presents the spatial distribution of precipitation averaged over the warm season. Since approximately $70 \%$ of the annual total precipitation is concentrated within only several months (June-July-August-September, hereinafter as JJAS), we focus on the different behaviors of precipitation simulated during JJAS hereinafter. First, the spatial details across different observations are different, reinforcing the uncertainty embedded in observation data. While the maximum in the southern coastal region is prominent, the shape and magnitude of other maxima in the northern part of South Korea differ noticeably from one another. For example, APHRODITE shows two separated, localized maxima, but precipitation from CRU and TRMM forms a broad band. For the quantitative aspect, the difference between TRMM and APHRODITE reaches more than $1 \mathrm{~mm} /$ day. Such a limited consistency may stem from different 
TABLE 2: Observation datasets used in this study.

\begin{tabular}{lccccc}
\hline Name & Version & Variable & Frequency & Resolution & Data source \\
\hline CRU & TS4.02 & Precipitation & Monthly & $0.5^{\circ} \times 0.5^{\circ}$ grid & Station-based \\
APHRODITE & V1801 & Precipitation & Daily & $0.25^{\circ} \times 0.25^{\circ}$ grid & Station-based \\
TRMM & 3B42 V7 & Precipitation & Monthly & $0.25^{\circ} \times 0.25^{\circ}$ grid & Satellite-based \\
KMA station & - & Precipitation & Daily & 56 stations over South Korea & In-situ station \\
\hline
\end{tabular}

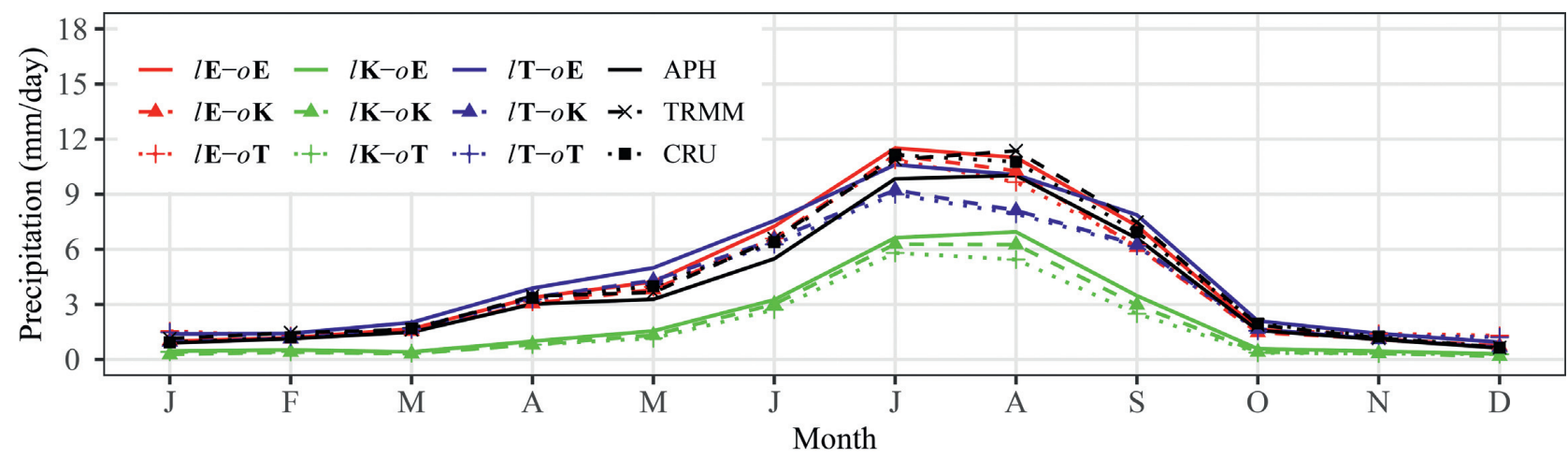

(a)

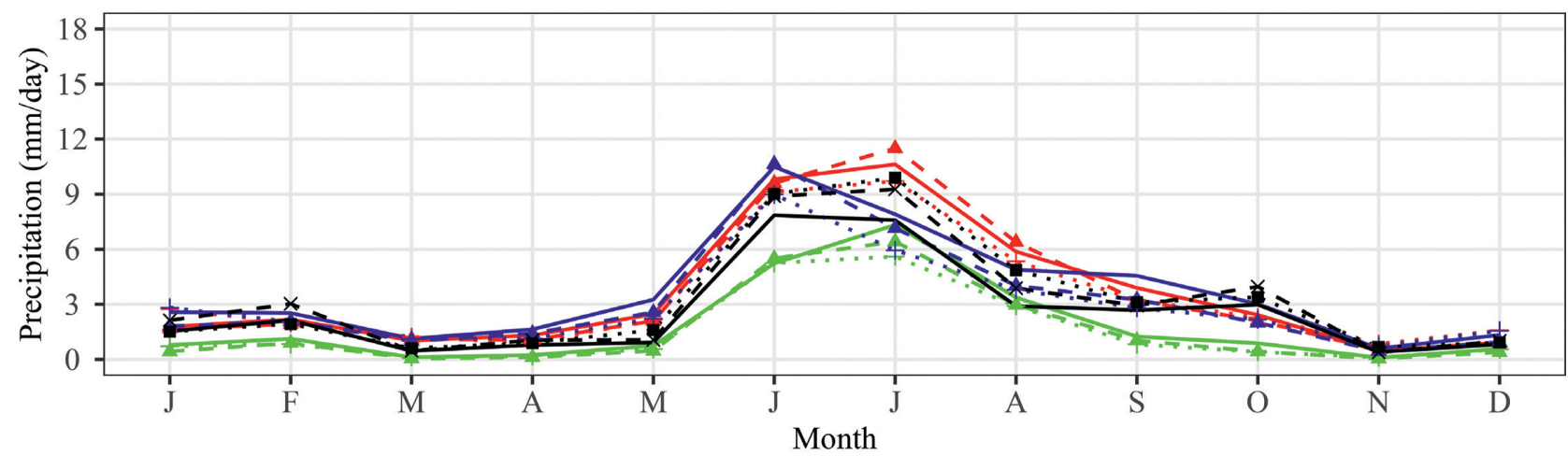

(b)

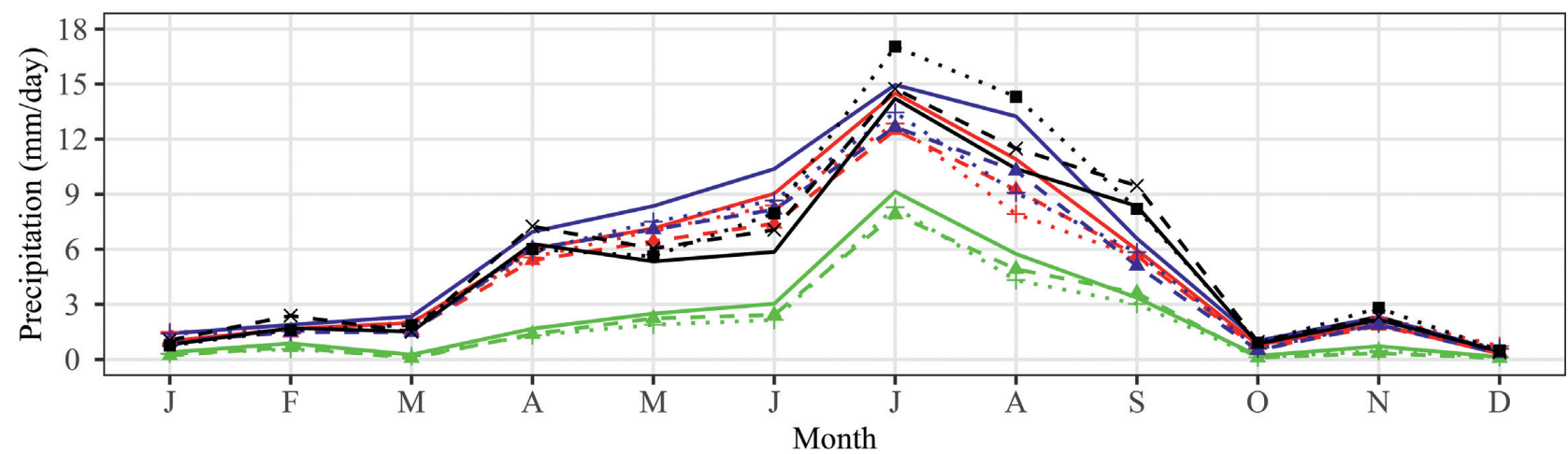

(c)

Figure 2: The annual cycle of monthly mean of daily precipitation (mm/day) for (a) the whole simulation period (1998-2007), (b) a dry year (2001), and (c) a wet year (2003). These data are derived from multiple observations and model simulations.

measurements and spatial resolutions. For the simulations, a very robust pattern is identified across the nine different sensitivity experiments. The CPS over land mostly determines the degree of quantitative error. The influence of the CPS over ocean seems to be relatively marginal. More specifically, the simulations with $l \mathbf{K}$ show significant dry 


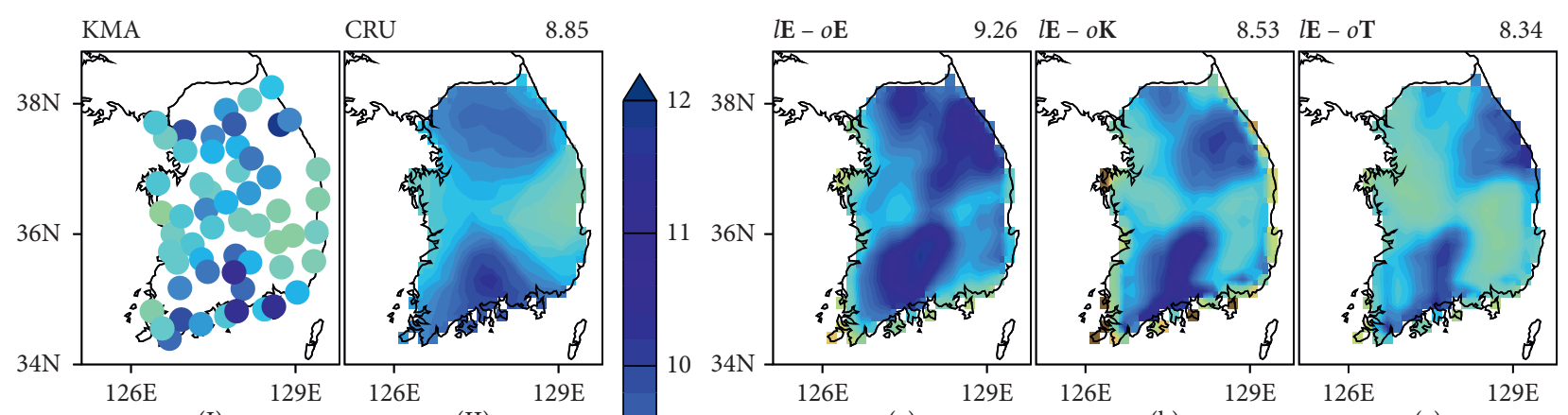

(I)

(II)
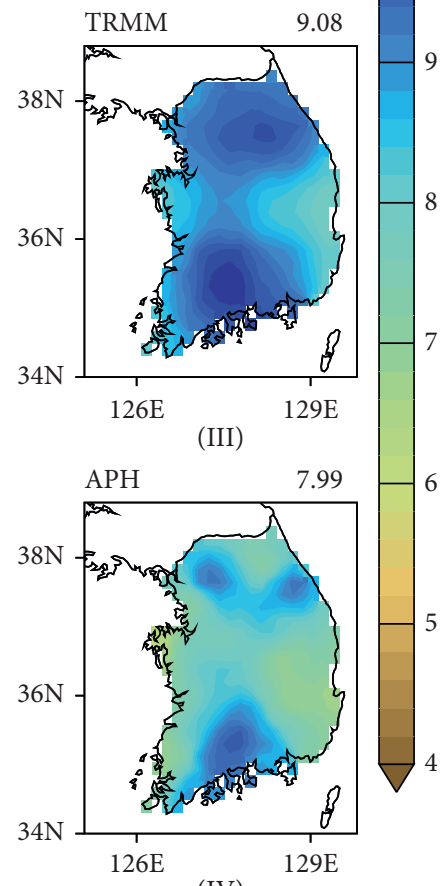

(IV)
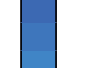

(b)

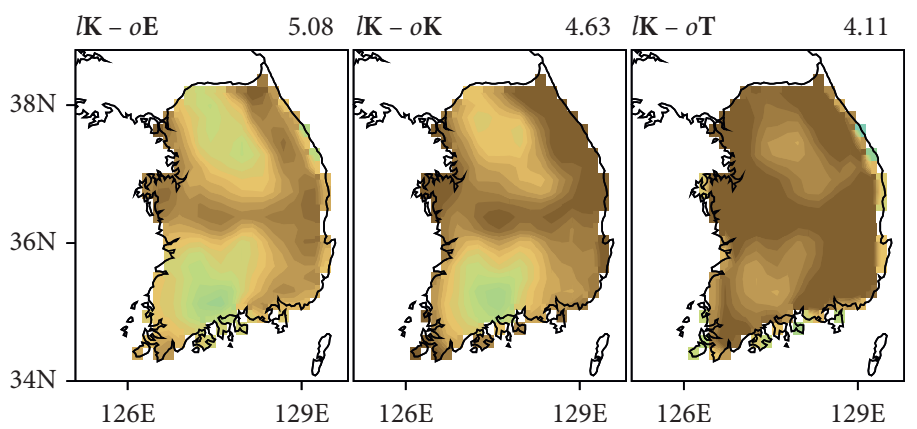

(d)

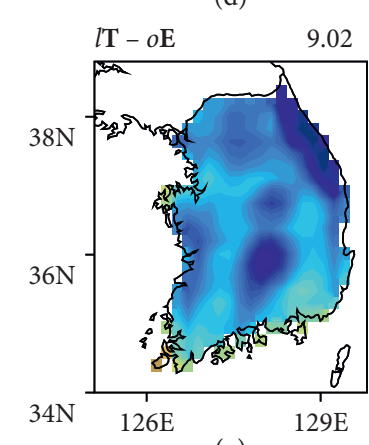

(g) (e)

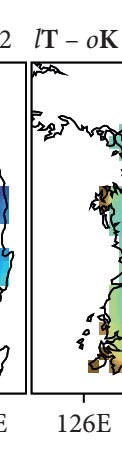

(f)

Figure 3: Spatial distribution of JJAS climatological mean precipitation (1998-2007, mm/day) derived from (I)-(IV) multiple observations and (a)-(i) model simulations. The number at the top-right of each panel is the mean precipitation area-averaged over South Korea land.

biases across the whole of South Korea (the second set of 3 rows in Table 3), despite having the best spatial correlation with the observations (see correlation coefficient in Table 3). For the simulations with $l \mathbf{E}$ and $l \mathbf{T}$ (the first and third sets of 3 rows in Table 3 ), the spatial-averaged precipitation amount is more reasonable compared with those with $l \mathbf{K}$. However, the simulations with $l \mathbf{E}$ and $l \mathbf{T}$ show some problematic behavior in the positioning of precipitation maxima. The excessive orographic precipitation occurs in the high-elevated mountains, particularly along the east coast in the simulations with $l \mathbf{T}$. This is responsible for the lower spatial correlation coefficient presented in Table 3. This may be caused by over-sensitivity of parameterization of rainfall processes to topography. Table 3 provides a statistical comparison of the overall performance of the nine sensitivity experiments against the gridded observations of APHRODITE, TRMM, and CRU. All experiments show mixed performance with both strengths and weaknesses when compared with the observation datasets. Moreover, the simulation with the best performance varies according to which observation data is used. Clearly, there is no single CPS that shows a superior performance across all comparisons. Nevertheless, $\boldsymbol{l} \mathbf{E}$ might be considered the most reasonable configuration, taking both quantitative and qualitative behaviors into considerations. The CPS over ocean, although not comparable with CPS over land, also affects the precipitation pattern over land through the advection of the convection system. The Tiedtke and KainFritsch scheme over ocean ( $o \mathbf{T}$ and $o \mathbf{K}$ ) tend to reduce the amount of precipitation over land.

To further quantitatively evaluate how the simulations deviate from observed patterns in terms of the probability across different intensities of monthly mean precipitation, the empirical cumulative distribution functions (ECDFs) of the simulations and the gridded observations are compared, and the Kolmogorov-Smirnov (KS) distance between them is calculated (Figure 4). KS distance measures the maximum distance between two distributions, and thus it can be a good indicator for estimating the level of similarity between the simulated and observed distribution. Consistent with the 
TABle 3: Statistical metrics for comparison of the June-July-August-September (JJAS) mean (1998-2007) precipitation between model simulations and multiple observations. Blue and red colors indicate the best and worst performance, respectively.

\begin{tabular}{|c|c|c|c|c|c|c|c|c|c|}
\hline \multirow{2}{*}{ Exp. } & \multicolumn{3}{|c|}{ APHRODITE } & \multicolumn{3}{|c|}{ TRMM } & \multicolumn{3}{|c|}{ CRU } \\
\hline & $\mathrm{ME}^{1}$ & $\mathrm{RMSE}^{2}$ & Corr. $^{3}$ & $\mathrm{ME}$ & RMSE & Corr. & $\mathrm{ME}$ & RMSE & Corr. \\
\hline$l \mathbf{E}-o \mathbf{E}$ & 1.27 & 1.61 & 0.51 & 0.18 & 0.98 & 0.52 & 0.41 & 1.17 & 0.35 \\
\hline$l \mathbf{E}-o \mathbf{K}$ & 0.54 & 1.31 & 0.51 & -0.55 & 1.32 & 0.51 & -0.32 & 1.31 & 0.40 \\
\hline$l \mathbf{E}-o \mathbf{T}$ & 0.35 & 0.86 & 0.55 & -0.74 & 1.09 & 0.46 & -0.51 & 1.00 & 0.41 \\
\hline$l \mathbf{K}-o \mathbf{E}$ & -2.91 & 2.98 & 0.59 & -4.00 & 4.03 & 0.61 & -3.77 & 3.81 & 0.61 \\
\hline$l \mathbf{K}-o \mathbf{K}$ & -3.35 & 3.43 & 0.58 & -4.44 & 4.48 & 0.63 & -4.21 & 4.26 & 0.64 \\
\hline$l \mathbf{K}-o \mathbf{T}$ & -3.87 & 3.97 & 0.24 & -4.96 & 5.03 & 0.18 & -4.73 & 4.80 & 0.24 \\
\hline$l \mathbf{T}-o \mathbf{E}$ & 1.03 & 1.58 & 0.15 & -0.06 & 1.13 & 0.13 & 0.17 & 1.31 & -0.11 \\
\hline$l \mathbf{T}-o \mathbf{K}$ & -0.47 & 1.25 & 0.22 & -1.55 & 1.87 & 0.29 & -1.33 & 1.80 & 0.04 \\
\hline$l \mathbf{T}-o \mathbf{T}$ & -0.65 & 1.39 & 0.22 & -1.74 & 2.11 & 0.15 & -1.51 & 2.00 & -0.01 \\
\hline
\end{tabular}

${ }^{1} \mathrm{ME}$ refers to mean error, and the unit is $\mathrm{mm} /$ day. ${ }^{2} \mathrm{RMSE}$ refers to root-mean-square error, and the unit is $\mathrm{mm} /$ day. ${ }^{3}$ Corr. refers to spatial correlation.

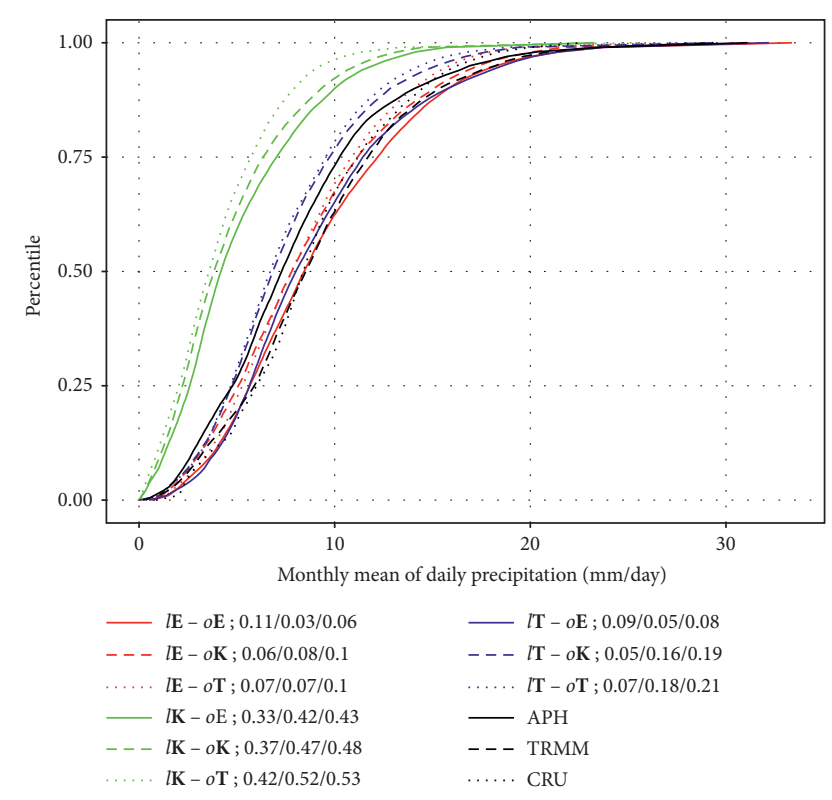

FIgURE 4: Empirical cumulative distribution function (ECDF) for monthly mean of daily precipitation ( $\mathrm{mm} /$ day) derived from multiple observations and model simulations. The values next to the name of each experiment are the Kolmogorov-Smirnov (KS) distance versus APHRODITE/TRMM/CRU.

results obtained from the analysis of spatial distribution seen in Figure 3, $l \mathbf{K}$ measures the largest KS distance away from the observed distribution due to the severe underestimation. The cumulative probability reaches the 50th percentile at a daily precipitation less than $5 \mathrm{~mm} /$ day. When comprehensively compared with the three observation datasets, $l \mathbf{E}-o$ $\mathbf{K}, l \mathbf{E}-o \mathbf{T}$, and $l \mathbf{T}-o \mathbf{E}$ are well matched in the light to heavy precipitation.

In summary, the different combinations of CPSs employed in the latest version of RegCM4 show the different performance in simulating the statistics of seasonal and monthly mean precipitation. The three major findings are (1) the influence of CPS over land overwhelms the CPS over ocean. (2) Simulation with $l \mathbf{K}$ is characterized by copious dry biases suggesting that it is not appropriate to apply this scheme over land in South Korea using the RegCM4. (3) Although there is no CPS that shows the best performance in both quantitative and qualitative comparisons, $l \mathbf{E}$ is regarded as the most reasonable configuration for the simulation of summer precipitation over South Korea.

3.2. Evaluation of the Daily Precipitation. On the gross pattern of monthly and seasonal mean precipitation against gridded and station observations, this section focuses on the performance of daily precipitation that can help in understanding the characteristics of the frequency, intensity, and extremes. For the simulation, we consider the case when a daily precipitation is higher than $0.1 \mathrm{~mm}$.

Figure 5 presents the time-latitude cross section of daily precipitation that is zonally averaged from $126^{\circ} \mathrm{E}$ to $129.5^{\circ} \mathrm{E}$. Because summer precipitation in East Asia, including the Korean Peninsula, propagates towards the north along the monsoon front, capturing its evolution plays an important role in improving the accuracy of model simulation. Both the observation datasets (i.e., APHRODITE and TRMM) clearly reveal that heavy precipitation, exceeding $16 \mathrm{~mm} /$ day, moves progressively towards the north from mid-June to early August. There are some localized stationary precipitation bands after the peak is reached (early August), but there is no relevant propagation at that time. A similar behavior is observed in all simulations; however, different CPSs yield the sensitivity of magnitude of the intense precipitation band. Again, the simulations with $l \mathbf{K}$ suffer from a severe dry bias, despite capturing the shape of the evolutionary pattern and the peak in early August. Other simulations with $l \mathbf{E}$ and $l \mathbf{T}$ deliver reasonable overall performance when the timing and amplitude of the precipitation band are simulated.

Given that nontrivial discrepancy exists in the different gridded observation datasets (i.e., APH and TRMM), the analysis presented below is based on the comparison with insitu observation data obtained from 56 KMA stations. For this, gridded model simulations are converted into 56 stations, as presented in Figure 1. Figure 6 presents the temporal evolution of daily mean precipitation averaged over the 56 stations during the four months (JJAS) throughout the 10-year period. In general, RegCM4 delivers a reasonable performance in simulating interannual and intraseasonal precipitation variations. The simulated and observed daily 

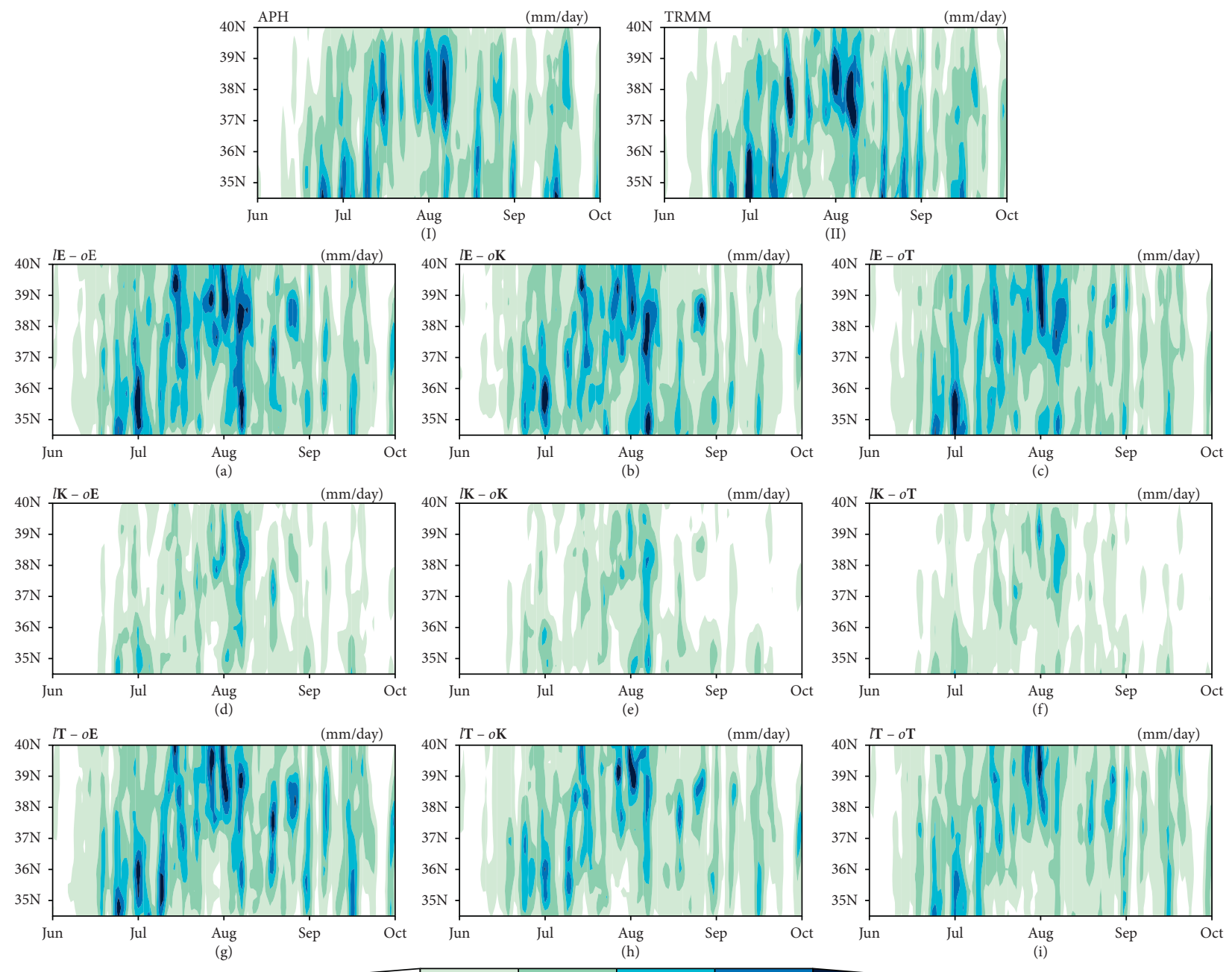

FIGURE 5: Time-latitude cross-sections of the 10-year JJAS period (1998-2007) mean daily precipitation (mm/day), zonally averaged over the Korean Peninsula ( $126^{\circ} \mathrm{E}$ to $129.5^{\circ} \mathrm{E}$ ), derived from: (I) APHRODITE, (II) TRMM, and (a)-(i) model simulations.

fluctuations are well correlated (the temporal correlation coefficient exceeds 0.7). Additionally, the simulations effectively capture the variations in daily mean precipitation occurring each year, including the timing of the precipitation peaks in different years. For example, the model successfully captures the extreme cases observed in 1998 and 2002 , except for the simulations with $l K$. In particular, $l \mathbf{E}-o \mathbf{E}$ outperforms the others based on the temporal correlation and the precipitation-peak intensity.

To further investigate the precipitation characteristics of each simulation, the analyses of the frequency and intensity of daily precipitation are presented in Figure 7. For the individual experiments and the in-situ observation, a data sample is created by pooling the 10-year JJAS daily values from all the 56 stations ( 122 days $\times 10$ years $\times 56$ stations) together. Using this sample, Figure $7(\mathrm{a})$ presents the frequency distribution of precipitation with respect to the intensity of precipitation with $10 \mathrm{~mm} /$ day intervals, whereas Figures 7(b) and 7(c) display the boxplot of daily precipitation and extreme precipitation to emphasize the difference at the tail parts that are not easily distinguished in
Figure 7(a). Firstly, the models exhibit the ability of capturing the gamma distribution of precipitation with similarity to the observed pattern. However, the performance variations increase as the intensity of precipitation increases. The $l \mathbf{K}$ simulations clearly underestimate the occurrence of precipitation with intensity exceeding $40 \mathrm{~mm} /$ day, whereas $l \mathrm{E}$ and $l \mathrm{~T}$ simulations are considerably closer to the observation. Such discrepancy is also observed in the boxplot of extreme daily precipitation above the $95^{\text {th }}$ percentile. Almost the entire box from $l \mathbf{K}$ simulations does not overlap with the observed one, which means that the statistics (e.g., median and interquartile range) between the simulation and observation are fairly different owing to the severe dry bias observed in the $l \mathbf{K}$ simulations.

To compare far clearer shape of extreme behavior, Figure 8 presents the boxplots with the annual maximum consecutive 5-day accumulative precipitation and the annual number of days when precipitation exceeds $20 \mathrm{~mm}$ /day in 56 individual stations (10years $\times 56$ stations) in case of each simulation. Consistently, the simulations with $l \mathbf{K}$ show the worst performance, underestimating both the mean and 

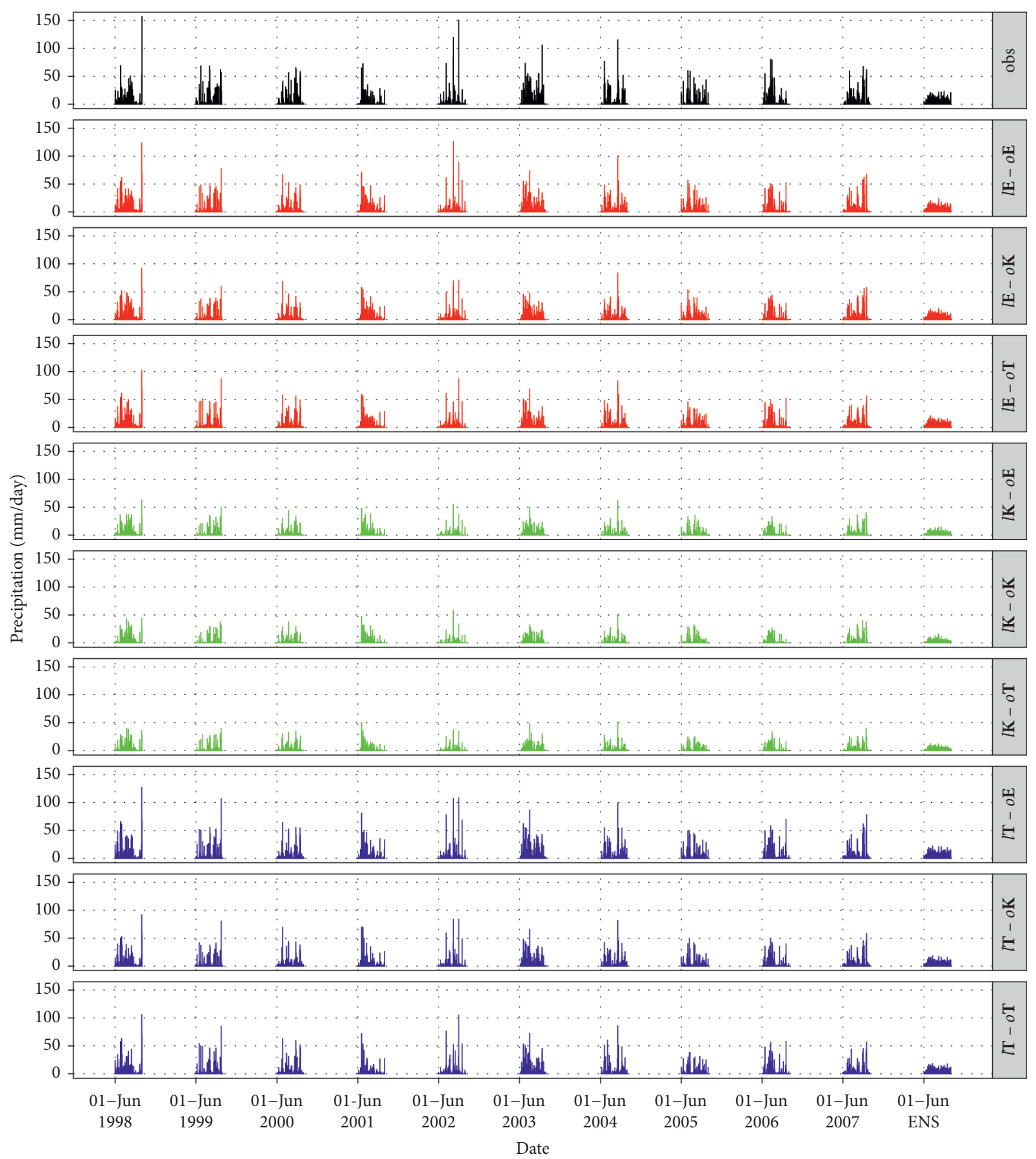

FIGURE 6: Time evolution of 56-station-averaged daily precipitation ( $\mathrm{mm} /$ day) for the 10-year JJAS period (1998-2007) and the ensemble of 10 years derived from the in-situ observation and model simulations interpolated to the station sites.

extremes. In contrast, $l \mathbf{E}-o \mathbf{E}$ and $l \mathbf{T}-o \mathbf{E}$ deliver the best performances, particularly reproducing extreme consecutive precipitation events over $500 \mathrm{~mm} / 5$-day. A comparison between Figures 7 and 8 indicates that the sensitivity of intense precipitation to CPS tends to be higher than that of weak precipitation to CPS. In addition, the effect of CPS on the ocean is evident in the case of extreme precipitation (Figure 8), whereas it is negligible in the case of mean precipitation. For example, the performance of $o \mathbf{E}$ is better than those of $o \mathbf{T}$ or $o \mathbf{K}$ in simulating extreme precipitation when the same CPS is employed for the land. Irrespective of the CPS that is applied, all the simulations fail to capture the very extreme cases when the precipitation amount for 5 days exceeds $550 \mathrm{~mm}$, which is possibly associated with a typhoon. As demonstrated in previous studies, most of the RCMs show a low accuracy when simulating heavy precipitation accompanied by a typhoon (e.g., Im et al. 2006 [5]).

In general, the analysis of daily precipitation provides more in-depth insights into the performance of each CPS. It 


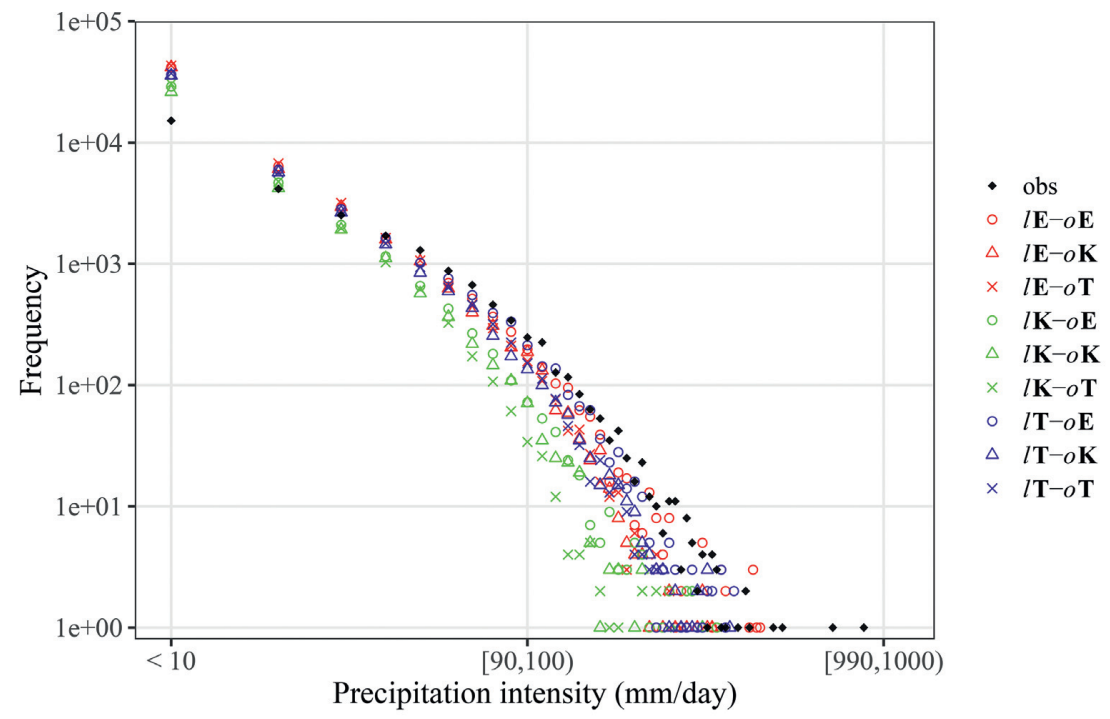

(a)

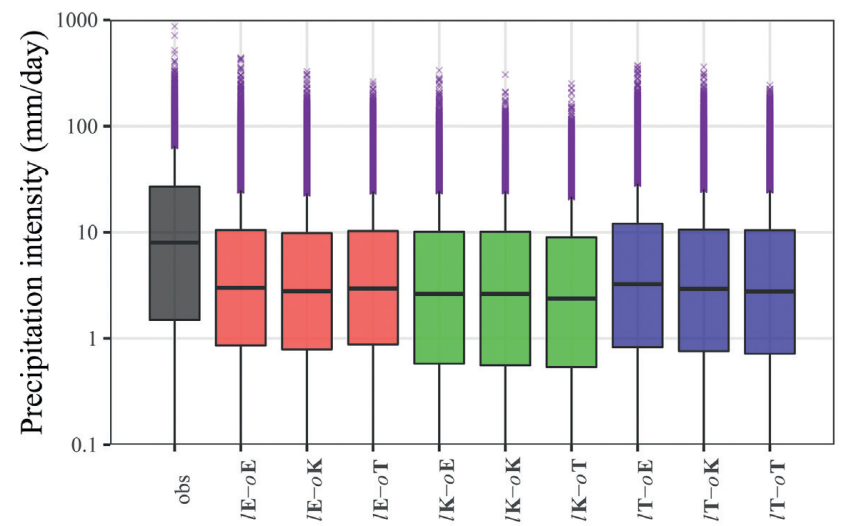

(b)

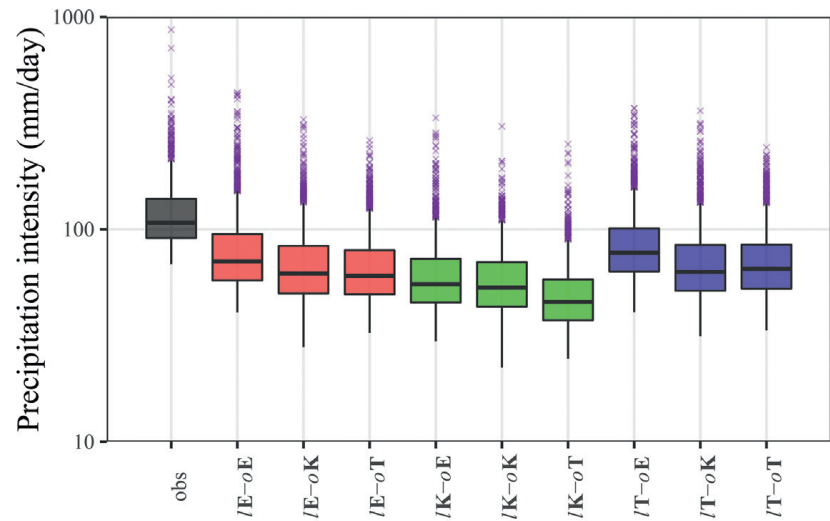

(c)

Figure 7: (a) Frequency distribution of daily precipitation and boxplot of (b) daily precipitation and (c) extreme daily precipitation exceeding the 95th percentile, derived from the in situ observation and model simulations interpolated to the station sites. The thick black line within each box represents the median value. The square bracket in (a) represents the precipitation intensity greater than or equal to the value, while the parenthesis represents the precipitation intensity less than the value.

reveals that although the simulations can capture the temporal and spatial variabilities of the daily precipitation, they still unavoidably overestimate the frequency of light precipitation and underestimate the frequency and intensity of the mid-to-high precipitation. Overall, $l \mathbf{E}-o \mathbf{E}$ and $l \mathbf{T}-o \mathbf{E}$ offer an advantage over the other CPSs in terms of the extreme daily precipitation.

\subsection{The Physical Mechanism behind the Precipitation Pattern.} To understand the physical processes underlying the different performance across the CPSs, two cases, $l \mathbf{E}-o \mathbf{E}$ and $l \mathbf{K}-o \mathbf{K}$, which represent the best and worst performances, respectively, are selected, and in-depth analyses of the thermodynamic and vertical structures are performed. First, we assess the relative contribution of convective precipitation to the total precipitation, given that CPS primarily controls the formation of convective precipitation. Figure 9 presents the spatial distribution of convective precipitation and its ratio with respect to total precipitation derived from $l$ $\mathbf{E}-o \mathbf{E}$ and $l \mathbf{K}-o \mathbf{K}$ simulations. In line with the amount of total precipitation (See Figures 3(a), 3(e)), the amount of convective precipitation is considerably higher in $l \mathbf{E}-o \mathbf{E}$ simulation than in $l \mathbf{K}-o \mathbf{K}$ simulation. It can be inferred from the spatial similarity in the maximum position between convective and total precipitations that convective precipitation derived from different CPSs can be a major factor in determining the performance of simulated precipitation in terms of magnitude and localized maxima. In contrast to the amount, interestingly, the ratio of convective precipitation to total precipitation exhibits an opposite pattern, yielding the higher values in $l \mathbf{K}-o \mathbf{K}$ simulation than in $l \mathbf{E}-o \mathbf{E}$ simulation. The $l \mathbf{K}-o \mathbf{K}$ produces convective precipitation exceeding $70 \%$ in large areas in the Korean Peninsula. However, it was reported that stratiform large-scale precipitation rather than convective precipitation is the 


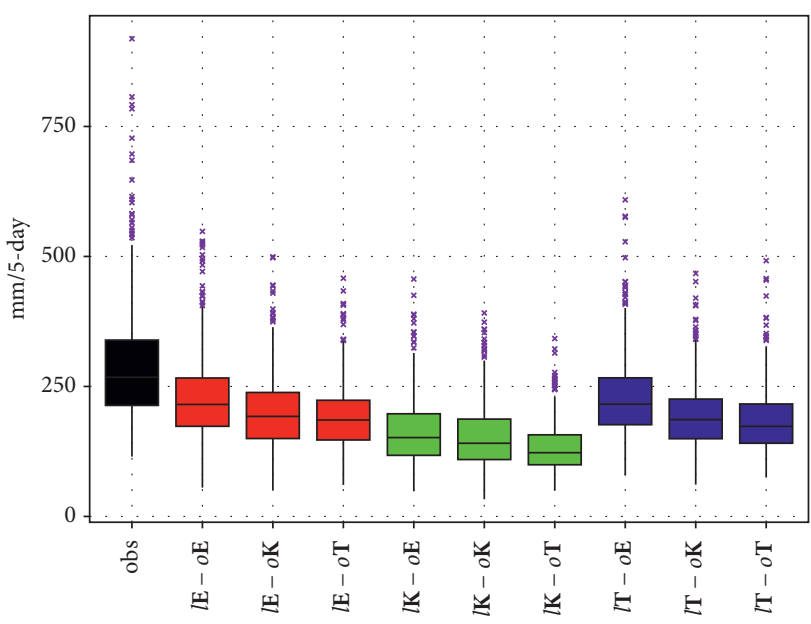

(a)

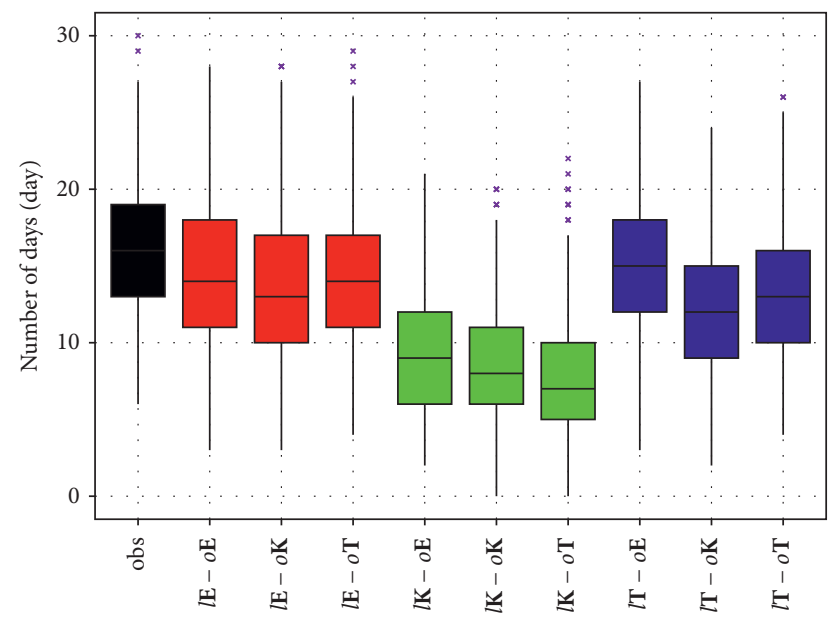

(b)

Figure 8: (a) Boxplots of annual maximum consecutive 5-day accumulative precipitation and (b) number of days with precipitation exceeding $20 \mathrm{~mm}$ /day using the 10 -year JJAS derived from the in-situ observation and model simulations interpolated to the station sites. The thick black line within each box represents the median value.

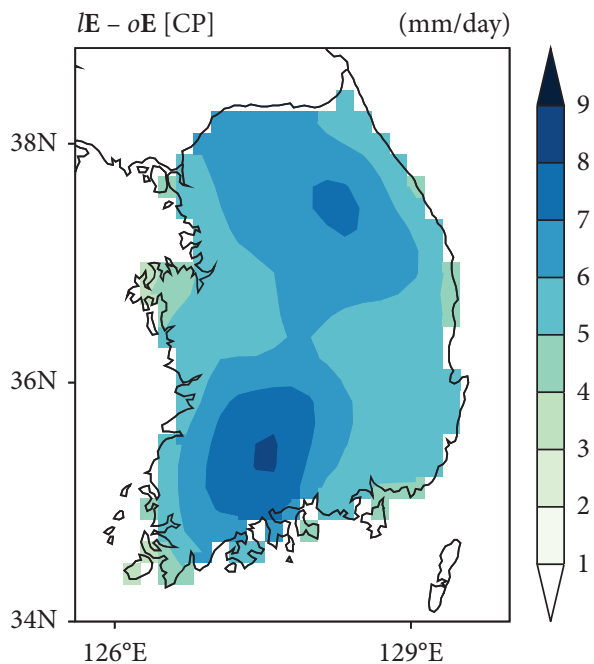

(a)

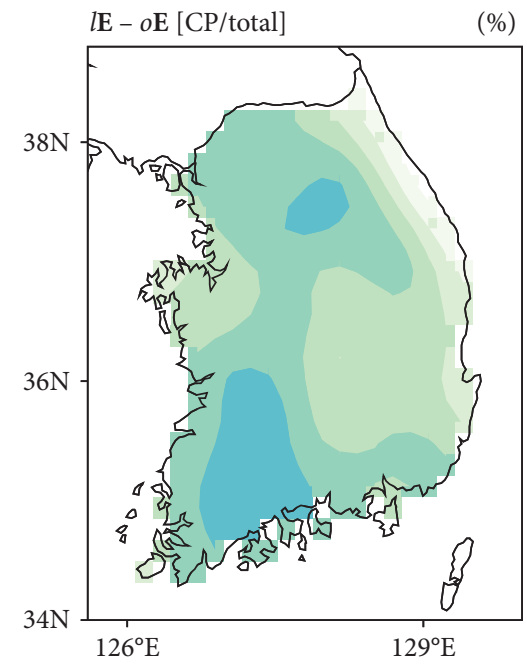

(c)

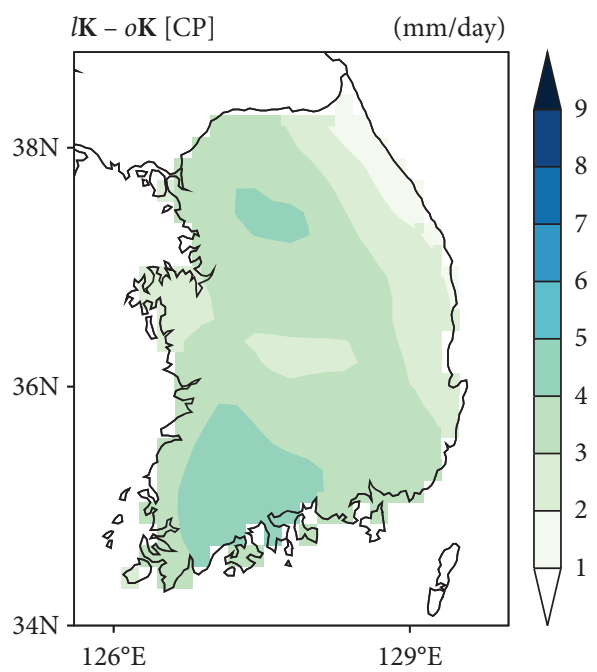

(b)

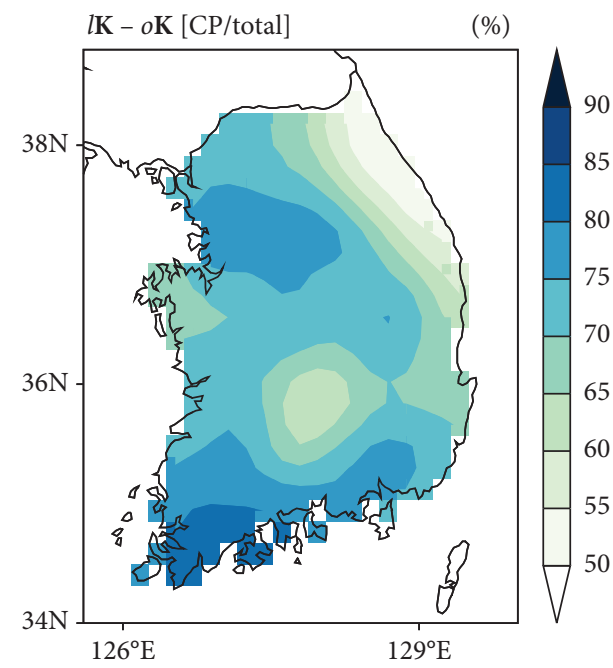

(d)

FIgURe 9: Spatial distribution of (a), (b) convective precipitation ( $\mathrm{mm} /$ day) and (c), (d) its ratio with respect to total precipitation (\%) derived from $l \mathbf{E}-o \mathbf{E}$ and $l \mathbf{K}-o \mathbf{K}$ simulations. 


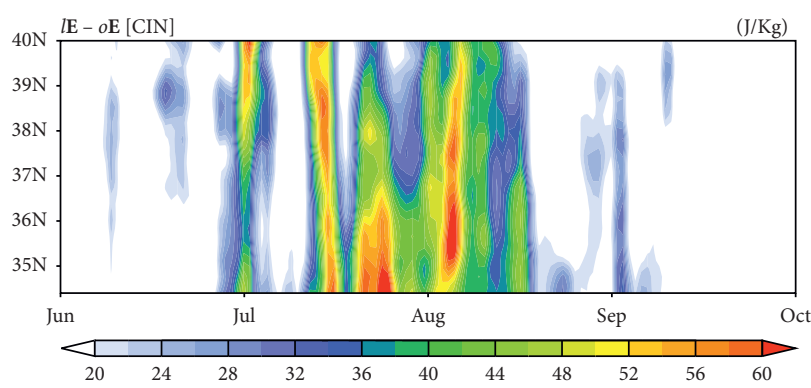

(a)

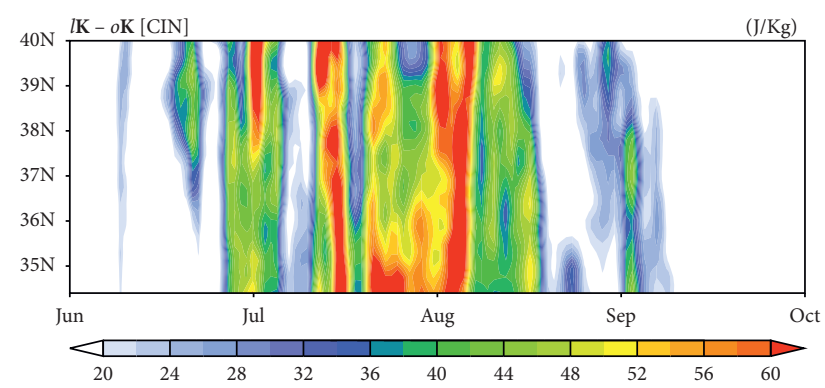

(b)

Figure 10: Time-latitude cross-sections of the 10-year JJAS period (1998-2007) daily CIN (J/kg), zonally averaged over the Korean Peninsula $\left(126^{\circ} \mathrm{E}\right.$ to $\left.129.5^{\circ} \mathrm{E}\right)$, derived from (a) $l \mathbf{E}-o \mathbf{E}$ and (b) $l \mathbf{K}-o \mathbf{K}$.

dominant precipitation type in Korea [47]. For $l \mathbf{K}-o \mathbf{K}$ simulation, a small amount of convective precipitation constitutes large parts of the total precipitation, and it leads to substantial dry biases in total precipitation. In this regard, $l \mathbf{E}-o \mathbf{E}$ shows a relatively better ability of capturing a realistic balance between the convective and large-scale precipitations. Note that although CPS plays a critical role in triggering and developing convective clouds at an unresolved subgrid scale, the modified vertical profiles of thermodynamic variables through the parameterization of convective precipitation can modulate the processes for resolved grid-scale precipitation. The partitioning of convective and large-scale precipitations is a result achieved from the active communication of both the processes within a model. Therefore, appropriate partitioning of convective precipitation plays a key role in the successful simulation of precipitation characteristics $[47,48]$.

Convective inhibition (CIN) may provide a clue for explaining the different amounts of convective precipitation derived from the two CPSs. Figure 10 presents the time-latitude cross-section of climatological (1998-2007: 10-year) daily CIN, zonally averaged from $126^{\circ} \mathrm{E}$ to $129.5^{\circ} \mathrm{E}$ for the month of June through September. Because CIN indicates the amount of energy inhibiting convection, a larger CIN indicates a more unfavorable condition for convection [49]. Consistent with the precipitation pattern appeared in Figure 5, the CIN calculated using the output from $l \mathbf{K}-o \mathbf{K}$ simulation is much higher than that from $l \mathbf{E}-o \mathbf{E}$ simulation. In particular, $l \mathbf{K}-o \mathbf{K}$ simulation exhibits a very high CIN at the timing when $l \mathbf{E}-o \mathbf{E}$ exhibits an intense precipitation band, explaining why $l \mathbf{K}-o \mathbf{K}$ simulation suffers from a substantial dry bias.

To minimize the smoothing effect arising from averaging in the temporal and spatial dimensions, daily CIN values from 56 stations in the 10-year JJAS period are pooled together and are counted into corresponding bins in the frequency distribution (Figure 11). The frequencies of CIN, which indicate atmospheric environments with weak and moderate inhibitions (CIN $<100 \mathrm{~J} / \mathrm{kg}$ ), are mostly the same in $l \mathbf{E}-o \mathbf{E}$ and $l \mathbf{K}-o \mathbf{K}$ simulations. However, their differences are more evident at the range with very high CIN because $l \mathbf{K}-o \mathbf{K}$ simulation has a longer and thicker tail. It means that CIN from $l \mathbf{K}-o \mathbf{K}$ simulation is often too high to trigger the convection, which directly results in the suppression of convective precipitation.
We also check the vertical structures of moisture content and omega simulated from $l \mathbf{E}-o \mathbf{E}$ and $l \mathbf{K}-o \mathbf{K}$ to further explain the different circumstance potentially responsible for the formation of precipitation. Figure 12 presents the vertical cross section of specific humidity and omega along the latitudes at $127.6^{\circ} \mathrm{E}$. A notable difference between the two simulations can be observed for low level moisture. The $l \mathbf{K}-o \mathbf{K}$ simulation tends to produce drier conditions in the level across entire latitude of the Korean Peninsula. Therefore, in spite of a stronger rising motion, the formation of clouds is fairly limited owing to a lack of moisture source. The higher values of CIN seen in Figure 11 are typically generated by the flow of dry air [49]. The thermodynamic and vertical structures described above collectively differentiate the performances of precipitation when employing different CPSs such as $l \mathbf{E}-o \mathbf{E}$ and $l \mathbf{K}-o \mathbf{K}$.

\section{Discussion and Conclusion}

The potential of the earlier version of RegCM to simulate the climate in Korea has been intensively examined $[4,6,27,50]$. This study provides an updated assessment of the latest version of RegCM4 by applying the newly implemented CPSs (i.e., the introduction of mixed convection schemes and the availability of Kain-Fritsch and Tiedtke schemes). We focus on the comparison of performances of nine sensitivity experiments, which have the different combinations of Emanuel, Kain-Fritsch, and Tiedtke schemes over land and ocean, in simulating the summer precipitation in South Korea. A comprehensive assessment, including the seasonal, monthly, and daily statistics against gridded and in situ observation datasets, is conducted to evaluate the model's performance with different CPS.

The monthly and seasonal climatological mean precipitations clearly indicate that the determination of spatial pattern and amount of precipitation is highly dependent on the CPS that is applied over land. Irrespective of the CPS that is applied over the ocean, the Kain-Fritsch scheme over land tends to suffer the most from severe dry bias, although it provides a high spatial correlation with the observations. It is revealed that the thermodynamic and vertical structures in $l \mathbf{K}-o \mathbf{K}$ simulation are unfavorable for triggering and developing the convection because the CIN is too high and moisture in low level is not sufficient, compared to $l \mathbf{E}-o \mathbf{E}$ 


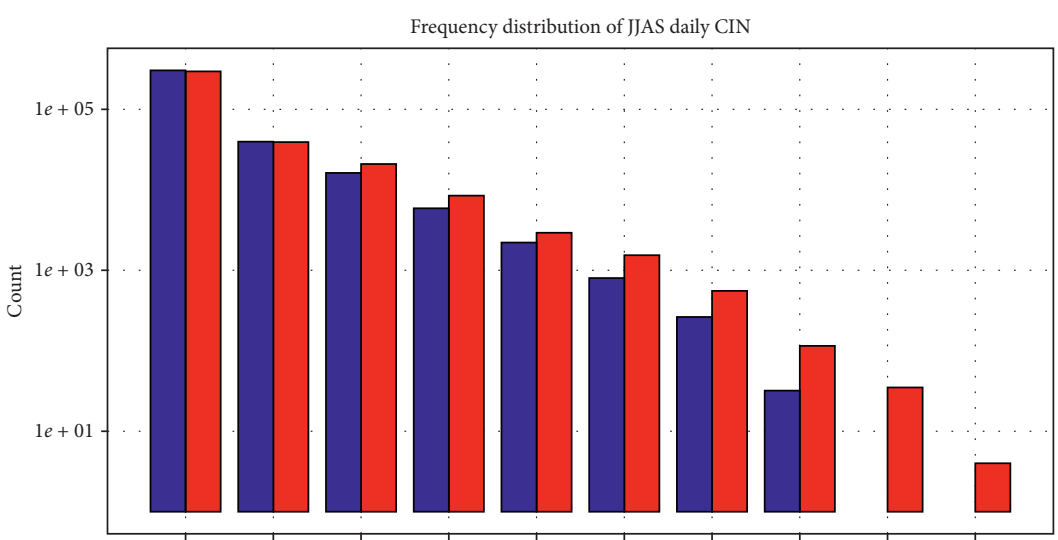

$[0 ; 50) \quad[50 ; 100)[100 ; 150)[150 ; 200)[200 ; 250)[250 ; 300)[300 ; 350)[350 ; 400)[400 ; 450)[450 ; 500)$

CIN

$l \mathrm{E}-o \mathbf{E}$
$l \mathbf{K}-o \mathbf{K}$

Figure 11: Frequency distribution of daily CIN (J/kg) during the 10-year JJAS period (1998-2007) from 56 stations over the Korean Peninsula derived from $l \mathbf{E}-o \mathbf{E}$ and $l \mathbf{K}-o \mathbf{K}$ simulations. The square bracket represents the CIN greater than or equal to the value, while the parentheses represent the CIN less than the value.

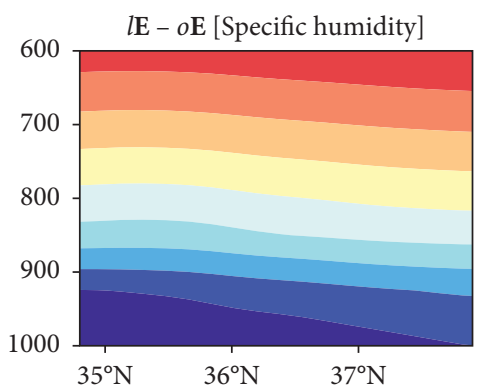

(a)

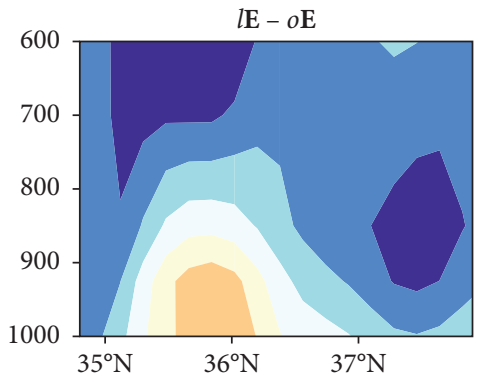

(d)

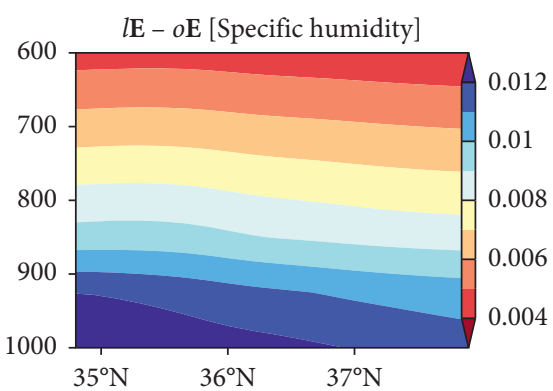

(b)

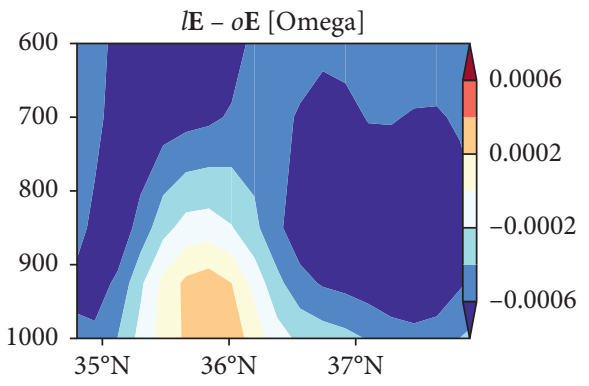

(e)

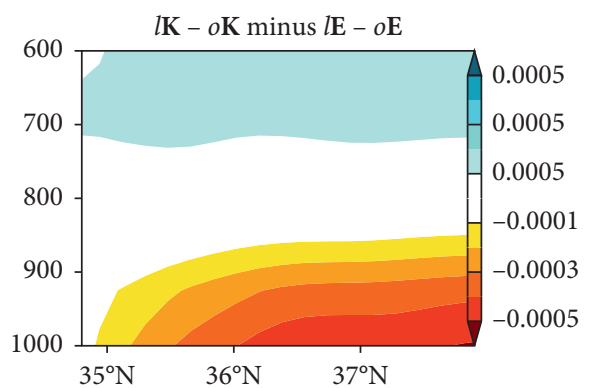

(c)

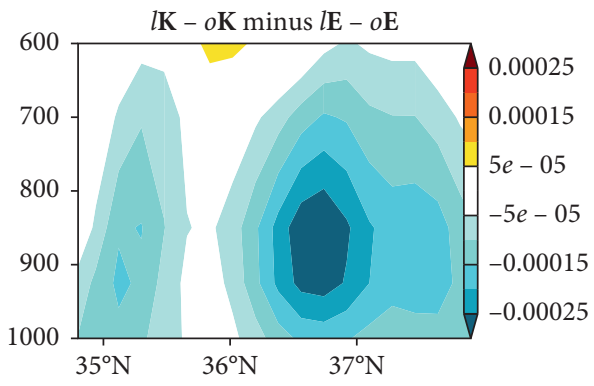

(f)

FIGURE 12: Vertical-latitudinal structure of (a), (b) climatological specific humidity (kg/kg) and (d), (e) omega (hPa/s) along the latitudes at $127.6^{\circ} \mathrm{E}$, and (c), (f) their differences derived from (a, d) $l \mathbf{E}-o \mathbf{E}$ and (b, e) $l \mathbf{K}-o \mathbf{K}$ simulations.

that delivers the most reasonable performance in this study. On the other hand, the Tiedtke scheme over land produces excessive orographic precipitation that ruins its reproduction of the spatial pattern. From this perspective, the Emanuel scheme over land is clearly superior in capturing the major characteristics of summer precipitation in South Korea. However, when applying the Emanuel scheme over both land and ocean, the precipitation tends to be slightly overestimated. Replacing it with the Tiedtke or Kain-Fritsch schemes over the ocean may alleviate this problem. For daily statistics, the Emanuel scheme over the ocean may benefit the simulation of extreme precipitation. Comparing with the Tiedtke or Kain-Fritsch schemes over the ocean, the results show good agreement with the observation in terms of heavy precipitation, especially when precipitation exceeds $500 \mathrm{~mm} /$ day.

An analysis of the 10-year sensitivity tests with different CPSs indicates that for the simulation of summer 
precipitation in South Korea using RegCM4, no CPS configuration exhibits an overall superiority across all the quantitative and qualitative aspects. The discrepancy among different observation datasets also makes it more difficult to derive a robust conclusion. Generally, the Emanuel scheme, which is the most frequently employed CPS in the Korea region, is still the best scheme over land and can capture the major characteristics of summer precipitation in this region. This study also demonstrates the merits of Tiedtke and Kain-Fritsch schemes, which are new additions to the recent versions of RegCM and have rarely been applied before, when employed when applied over the ocean in this region. Therefore, model users should take these findings into careful consideration when determining the CPS that best aligns with the purpose of their simulations.

\section{Data Availability}

The data that support the findings of this study are available from the corresponding author upon reasonable request.

\section{Conflicts of Interest}

The authors declare that there are no conflicts of interest regarding the publication of this paper.

\section{Acknowledgments}

Im E-S, Nguyen-Xuan T, and Qiu L were supported by the Korea Environment Industry and Technology Institute (KEITI) through the Advanced Water Management Research Program, which was funded by the Korea Ministry of Environment (MOE) (Grant 83079). This study was also partly carried out with the support of "Research Program for Agricultural Science and Technology Development (Project no. PJ014882)" and the National Institute of Agricultural Sciences, Rural Development Administration, Republic of Korea.

\section{References}

[1] S.-Y. Hong, N.-K. Moon, K.-S. S. Lim, and J.-W. Kim, "Future climate change scenarios over Korea using a multi-nested downscaling system: a pilot study," Asia-Pacific Journal of Atmospheric Sciences, vol. 46, no. 4, pp. 425-435, 2010.

[2] E.-S. Im and J.-B. Ahn, "On the elevation dependency of present-day climate and future change over Korea from a high resolution regional climate simulation," Journal of the Meteorological Society of Japan, vol. 89, no. 1, pp. 89-100, 2011.

[3] J.-W. Lee and S.-Y. Hong, "Potential for added value to downscaled climate extremes over Korea by increased resolution of a regional climate model," Theoretical and Applied Climatology, vol. 117, no. 3-4, pp. 667-677, 2014.

[4] S. Kang, E.-S. Im, and J.-B. Ahn, "The impact of two landsurface schemes on the characteristics of summer precipitation over East Asia from the RegCM4 simulations," International Journal of Climatology, vol. 34, no. 15, pp. 3986-3997, 2014.

[5] E.-S. Im, E.-H. Park, W.-T. Kwon, and F. Giorgi, "Present climate simulation over Korea with a regional climate model using a one-way double-nested system," Theoretical and Applied Climatology, vol. 86, no. 1-4, pp. 187-200, 2006.

[6] S.-G. Oh, J.-H. Park, S.-H. Lee, and M.-S. Suh, "Assessment of the RegCM4 over East Asia and future precipitation change adapted to the RCP scenarios," Journal of Geophysical Research: Atmospheres, vol. 119, no. 6, pp. 2913-2927, 2014.

[7] C. Park, S.-K. Min, D. Lee et al., "Evaluation of multiple regional climate models for summer climate extremes over East Asia," Climate Dynamics, vol. 46, no. 7-8, pp. 2469-2486, 2016.

[8] S.-G. Oh and M.-S. Suh, "Changes in seasonal and diurnal precipitation types during summer over South Korea in the late twenty-first century (2081-2100) projected by the RegCM4.0 based on four RCP scenarios," Climate Dynamics, vol. 51, no. 7-8, pp. 3041-3060, 2018.

[9] M.-H. Lee, M. Lu, E.-S. Im, and D.-H. Bae, "Added value of dynamical downscaling for hydrological projections in the Chungju Basin, Korea," International Journal of Climatology, vol. 39, no. 1, pp. 516-531, 2018.

[10] T.-Y. Lee and Y.-H. Kim, "Heavy precipitation systems over the Korean peninsula and their classification," Asia-Pacific Journal of the Atmospheric Sciences, vol. 43, no. 4, pp. 367396, 2007.

[11] B. J. Sohn, G.-H. Ryu, H.-J. Song, and M.-L. Ou, "Characteristic features of warm-type rain producing heavy rainfall over the Korean peninsula inferred from TRMM measurements," Monthly Weather Review, vol. 141, no. 11, pp. 3873-3888, 2013.

[12] E. Jo, C. Park, S.-W. Son, J.-W. Roh, G.-W. Lee, and Y.-H. Lee, "Classification of localized heavy rainfall events in South Korea," Asia-Pacific Journal of Atmospheric Sciences, 2019.

[13] J. Choi, J. Lee, and S. Kim, "Impact of sea surface temperature and surface air temperature on maximizing typhoon rainfall: focusing on typhoon maemi in Korea," Advances in Meteorology, vol. 2019, Article ID 1930453, 12 pages, 2019.

[14] F. Giorgi, "Thirty years of regional climate modeling: where are we and where are we going next?" Journal of Geophysical Research: Atmospheres, vol. 124, no. 11, pp. 5696-5723, 2019.

[15] Y. Xue, Z. Janjic, J. Dudhia, R. Vasic, and F. De Sales, "A review on regional dynamical downscaling in intraseasonal to seasonal simulation/prediction and major factors that affect downscaling ability," Atmospheric Research, vol. 147-148, no. 1-15, pp. 68-85, 2014.

[16] Y.-B. Li, C.-Y. Tam, W.-R. Huang, K. K. W. Cheung, and Z. Gao, "Evaluating the impacts of cumulus, land surface and ocean surface schemes on summertime rainfall simulations over Eastto-Southeast Asia and the Western North Pacific by RegCM4," Climate Dynamics, vol. 46, no. 7-8, pp. 2487-2505, 2016.

[17] D. Liu, B. Yang, Y. Zhang et al., "Combined impacts of convection and microphysics parameterizations on the simulations of precipitation and cloud properties over Asia," Atmospheric Research, vol. 212, pp. 172-185, 2018.

[18] N. D. Thanh, F. T. Tangang, J. Santisirisomboon et al., "Performance evaluation of RegCM4 in simulating extreme rainfall and temperature indices over the CORDEX-Southeast Asia region," International Journal of Climatology, vol. 37, no. 3, pp. 1634-1647, 2017.

[19] N. Elguindi, X. Bi, F. Giorgi et al., Regional Climate Model RegCM Reference Manual Version 4.6, The Abdus Salam International Centre for Theoretical Physics, Trieste, Italy, 2014.

[20] S. Ali, L. Dan, C. Fu, and Y. Yang, "Performance of convective parameterization schemes in Asia using RegCM: simulations 
in three typical regions for the period 1998-2002," Advances in Atmospheric Sciences, vol. 32, no. 5, pp. 715-730, 2015.

[21] S. Maity, A. N. V. Satyanarayana, M. Mandal, and S. Nayak, "Performance evaluation of land surface models and cumulus convection schemes in the simulation of Indian summer monsoon using a regional climate model," Atmospheric Research, vol. 197, no. 4, pp. 21-41, 2017.

[22] D. Martínez-Castro, A. Vichot-Llano, A. Bezanilla-Morlot et al., "The performance of RegCM4 over the Central America and Caribbean region using different cumulus parameterizations," Climate Dynamics, vol. 50, no. 11-12, pp. 4103-4126, 2018.

[23] M. Reboita, J. Fernandez, M. Pereira Llopart, R. Porfirio da Rocha, L. Albertani Pampuch, and F. Cruz, "Assessment of RegCM4.3 over the CORDEX South America domain: sensitivity analysis for physical parameterization schemes," Climate Research, vol. 60, no. 3, pp. 215-234, 2014.

[24] P. Sinha, R. K. S. Maurya, M. R. Mohanty, and U. C. Mohanty, "Inter-comparison and evaluation of mixed-convection schemes in RegCM4 for Indian summer monsoon simulation," Atmospheric Research, vol. 215, pp. 239-252, 2019.

[25] J. Chen, Y. Yin, Q. Chen, H. Ding, and H. Xiao, "Effect of convection schemes on the simulation of monsoon climates: a sensitivity study using RegCM4," Climate Research, vol. 60, no. 2, pp. 147-162, 2014.

[26] R. Fuentes-Franco, F. Giorgi, E. Coppola, and K. Zimmermann, "Sensitivity of tropical cyclones to resolution, convection scheme and ocean flux parameterization over Eastern Tropical Pacific and Tropical North Atlantic Oceans in the RegCM4 model," Climate Dynamics, vol. 49, no. 1-2, pp. 547-561, 2017.

[27] E.-S. Im, J.-B. Ahn, A. R. Remedio, and W.-T. Kwon, "Sensitivity of the regional climate of East/Southeast Asia to convective parameterizations in the RegCM3 modelling system. Part 1: focus on the Korean peninsula," International Journal of Climatology, vol. 28, no. 14, pp. 1861-1877, 2008.

[28] F. Giorgi, E. Coppola, F. Solmon et al., "RegCM4: model description and preliminary tests over multiple CORDEX domains," Climate Research, vol. 52, pp. 7-29, 2012.

[29] H. L. Kuo, "Further studies of the parameterization of the influence of cumulus convection on large-scale flow," Journal of the Atmospheric Sciences, vol. 31, no. 5, pp. 1232-1240, 1974.

[30] G. A. Grell, "Prognostic evaluation of assumptions used by cumulus parameterizations," Monthly Weather Review, vol. 121, no. 3, pp. 764-787, 1993.

[31] K. A. Emanuel and M. Ž.nd elf Exact49, "Development and evaluation of a convection scheme for use in climate models," Journal of the Atmospheric Sciences, vol. 56, no. 11, pp. 1766-1782, 1999.

[32] M. Tiedtke, "A comprehensive mass flux scheme for cumulus parameterization in large-scale models," Monthly Weather Review, vol. 117, no. 8, pp. 1779-1800, 1989.

[33] J. S. Kain, S. J. Weiss, D. R. Bright et al., "Some practical considerations regarding horizontal resolution in the first generation of operational convection-allowing NWP," Weather and Forecasting, vol. 23, no. 5, pp. 931-952, 2008.

[34] S. G. Oh, M.-S. Suh, J.-S. Myoung, and D.-H. Cha, "Impact of boundary conditions and cumulus parameterization schemes on regional climate simulation over South-Korea in the CORDEX-East Asia domain using the RegCM4 model," Journal of the Korean Earth Science Society, vol. 32, 2011 in Korean.
[35] J. T. Kiehl, J. J. Hack, G. B. Bonan et al., Description of NCAR Community Climate Model (CCM3): NCAR Technical Note NCAR/TN-420+STR, NCAR, Boulder, CO, USA, 1996.

[36] A. A. M. Holtslag, E. I. F. De Bruijn, and H.-L. Pan, "A high resolution air mass transformation model for short-range weather forecasting," Monthly Weather Review, vol. 118, no. 8, pp. 1561-1575, 1990.

[37] J. S. Pal, E. E. Small, and E. A. B. Eltahir, "Simulation of regional-scale water and energy budgets: representation of subgrid cloud and precipitation processes within RegCM," Journal of Geophysical Research: Atmospheres, vol. 105, no. D24, pp. 29579-29594, 2000.

[38] X. Zeng, M. Zhao, and R. E. Dickinson, "Intercomparison of bulk aerodynamic algorithms for the computation of sea surface fluxes using TOGA COARE and TAO data," Journal of Climate, vol. 11, no. 10, pp. 2628-2644, 1998.

[39] K. W. Oleson and D. M. Lawrence, Technical Description of Version 4.5 of the Community Land Model (CLM): NCAR Technical Note NCAR/TN-503+STR, NCAR, Boulder, CO, USA, 2013.

[40] D. P. Dee, S. M. Uppala, A. J. Simmons et al., "The ERAInterim reanalysis: configuration and performance of the data assimilation system," Quarterly Journal of the Royal Meteorological Society, vol. 137, no. 656, pp. 553-597, 2011.

[41] I. Harris, P. D. Jones, T. J. Osborn, and D. H. Lister, "Updated high-resolution grids of monthly climatic observations-the CRU TS3.10 Dataset," International Journal of Climatology, vol. 34, no. 3, pp. 623-642, 2014.

[42] A. Yatagai, K. Kamiguchi, O. Arakawa, A. Hamada, N. Yasutomi, and A. Kitoh, "APHRODITE: constructing a long-term daily gridded precipitation dataset for Asia based on a dense network of rain gauges," Bulletin of the American Meteorological Society, vol. 93, no. 9, pp. 1401-1415, 2012.

[43] G. J. Huffman, D. T. Bolvin, E. J. Nelkin et al., “The TRMM multisatellite precipitation analysis (TMPA): quasi-global, multiyear, combined-sensor precipitation estimates at fine scales," Journal of Hydrometeorology, vol. 8, no. 1, pp. 38-55, 2007.

[44] G. J. Huffman, R. F. Adler, D. T. Bolvin, and E. J. Nelkin, “The TRMM multi-satellite precipitation analysis (TMPA) BT," in Satellite Rainfall Applications for Surface Hydrology, M. Gebremichael and F. Hossain, Eds., Springer, Dordrecht, Netherlands, pp. 3-22, 2010.

[45] Korean Meteorological Administration (KMA), Annual Report 2017. Korea Meteorological Administration, Korean Meteorological Administration (KMA), Seoul, Republic of Korea, 2018.

[46] L. Juneng, F. Tangang, J. Chung et al., "Sensitivity of Southeast Asia rainfall simulations to cumulus and air-sea flux parameterizations in RegCM4," Climate Research, vol. 69, no. 1, pp. 59-77, 2016.

[47] I.-H. Park and S.-K. Min, "Role of convective precipitation in the relationship between subdaily extreme precipitation and temperature," Journal of Climate, vol. 30, no. 23, pp. 95279537, 2017.

[48] L. Qiu, E.-S. Im, J. Hur, and K.-M. Shim, “Added value of very high resolution climate simulations over South Korea using WRF modeling system," Climate Dynamics, vol. 54, no. 1-2, pp. 173-189, 2019.

[49] K. L. Rasmussen, A. F. Prein, R. M. Rasmussen, K. Ikeda, and C. Liu, "Changes in the convective population and thermodynamic environments in convection-permitting regional climate simulations over the United States," Climate Dynamics, 2017. 
[50] E.-S. Im, Y.-W. Choi, and J.-B. Ahn, "Worsening of heat stress due to global warming in South Korea based on multi-RCM ensemble projections," Journal of Geophysical Research: Atmospheres, vol. 122, no. 21, pp. 11444-11461, 2017. 